\title{
Decadal comparison of a diminishing coral community: a case study using demographics to advance inferences of community status
}

Margaret Miller, Dana E Williams, Brittany E Huntington, Gregory A Piniak, Mark JA Vermeij

The most common coral monitoring methods estimate coral abundance as percent cover, either via in situ observations or derived from images. In recent years, growing interest and effort has focused on colony-based (demographic) data to assess the status of coral populations and communities. In this study, we infer changes in coral communities from two separate data sets (photo-derived percent cover estimates, 2002-12, and opportunistic in situ demographic sampling, 2004 and 2012) in order to more fully understand the decade-scale changes observed at a small, uninhabited Caribbean island. Photo-derived percent cover documented drastic declines in coral abundance including disproportionate declines in Orbicella spp. While overall in situ estimates of total coral density were not different between years, densities of several rarer taxa were. Meandrina meandrites and Stephanocoenia intersepta increased while Leptoseris cucullata decreased significantly, changes that were not discernable from the photo-derived cover estimates. Demographic data also showed significant shifts to larger colony sizes (both increased mean colony sizes and increased negative skewness of size frequency distributions, but similar maximum colony sizes) for most taxa likely indicating reduced recruitment. Orbicella spp. differed from this general pattern, significantly shifting to smaller colony sizes due to partial mortality. Both approaches detected significant decadal changes in coral community structure at Navassa, though the demographic sampling provided better resolution of more subtle, taxon-specific changes. 
Decadal comparison of a diminishing coral community: a case study using demographics to advance inferences of community status

ABSTRACT: The most common coral monitoring methods estimate coral abundance as percent cover, either via in situ observations or derived from images. In recent years, growing interest and effort has focused on colony-based (demographic) data to assess the status of coral populations and communities. In this study, we relied on two separate data sets (photo-derived percent cover estimates, 2002-12, and opportunistic in situ demographic sampling, 2004 and 2012) to more fully infer decadal changes in coral communities at a small, uninhabited Caribbean island. Photo-derived percent cover documented drastic declines in coral abundance including disproportionate declines in Orbicella spp. While overall in situ estimates of total coral density were not different between years, densities of several rarer taxa were. Meandrina meandrites and Stephanocoenia intersepta increased while Leptoseris cucullata decreased significantly, changes that were not discernable from the photo-derived cover estimates. Demographic data also showed significant shifts to larger colony sizes (both increased mean colony sizes and increased negative skewness of size frequency distributions, but similar maximum colony sizes) for most taxa likely indicating reduced recruitment. Orbicella spp. differed from this general pattern, significantly shifting to smaller colony sizes due to partial mortality. Both approaches detected significant decadal changes in coral community structure at Navassa, though the demographic sampling provided better resolution of more subtle, taxonspecific changes.

Miller MW ${ }^{*}$, Williams DE ${ }^{1,2}$, Huntington BE ${ }^{1,2,3}$, Piniak $\mathrm{GA}^{4}$, Vermeij MJA ${ }^{5}$

1) NOAA/National Marine Fisheries Service, Southeast Fisheries Science Center, 75 Virginia Beach Dr. Miami FL 33149 USA. <Margaret.w.miller@noaa.gov>

2) Cooperative Institute for Marine and Atmospheric Studies, University of Miami, Miami,

28 Florida, USA

29 3) Current address: Oregon Dept Fish and Wildlife, Newport OR, USA

30 4) National Centers for Coastal Ocean Science, Silver Spring, MD 20910, USA.

31 5) CARMABI Foundation, Willemstad, Curaçao, Netherlands Antilles.

$32 *$ Corresponding 


\section{INTRODUCTION:}

Coral cover and community composition have been established as the standard metrics

36 for reef monitoring programs. Visual census techniques have been around for decades (Stoddart

$37 \&$ Johannes 1978), and gained early recognition for their utility in understanding population

38 dynamics (Hughes 1984) and disturbance/recovery dynamics (e.g., Done 1985). These

39 techniques provide a valuable, albeit general, overview of the status of reef communities, but

40 offer little insight on the processes that drive the observed patterns. Coral cover also carries

41 relatively low signal:noise ratio in depauperate reef areas (e.g. $<10 \%$ or even $1-2 \%$ cover) as is

42 characteristic of many modern Atlantic/Caribbean reefs (Jackson et al. 2014), making change

43 detection difficult without substantive (and perhaps unrealistic) increase in sample size (Molloy

44 et al. 2013). As a result, there has been increasing interest (and implementation) in expanding

45 from simple percent cover to more refined, process-based measures.

46 Coral demographic parameters have only recently been included in comprehensive coral

47 monitoring programs but may be a valuable supplement to percent cover data, as a demographic

48 approach offers species-specific and mechanistic insights into observed changes in percent cover.

49 Regional programs in south Florida (e.g., Smith et al. 2011; and Florida Reef Resillience

50 Program, frrp.org/coral-monitoring) and internationally (e.g., Atlantic and Gulf Rapid Reef

51 Assessment: Lang \& Ginsburg 2006; IUCN: Obura \& Grimsditch 2009) began implementing

52 colony based size and density measures in the early-mid 2000s. There is a wealth of ecological

53 theory to support analysis and interpretation of coral colony-based demographic data (Bak \&

54 Meesters 1998; Vermeij \& Bak 2002) whereby changes in the size structure of a population is

55 used to infer underlying ecological processes. Meanwhile, the collection of such data over large

56 programs and time frames carries some potential challenges such as inter-observer variation in 
57 detection (especially of small corals), uncertainty in species identification (especially of small

58 colonies), and consistently delineating colony boundaries in populations with large amounts of

59 partial mortality.

60 In this study, we analyze coral information derived from both percent cover data and

61 from demographic data collected at haphazardly selected reef sites to examine temporal change

62 in coral status at Navassa, a small, uninhabited Caribbean island. Reefs in this area have suffered

63 severe disturbances, including hurricane impacts, severe disease outbreaks, and mass bleaching

64 over the past decade resulting in a drastic loss of live coral cover (Miller et al. 2008a). We

65 present coral percent cover data using standard photo-quadrat techniques (collected in 2002,

$662004,2006,2009,2012)$ in parallel with a separate coral demographic data set collected in 2004

67 and 2012. Our purpose is not to compare between these sampling methods per se, as choice of

68 method is influenced not only by practical considerations (level of effort, etc) but also the type of

69 information desired and applicability within a habitat type. Rather, we examine these data sets

70 (the only in situ data available from reefs of this uninhabited island) in parallel to address two

71 questions: 1) Are observed changes in coral community status consistent between these two data

72 sets (i.e. cover versus colony density and size structure); and 2) Does the demographic data

73 provide insights on processes underlying observed changes that are not evident from the cover

74 data alone?

METHODS:

The small oceanic island of Navassa $\left(18.40^{\circ} \mathrm{N},-75.01^{\circ} \mathrm{W}\right)$ is a component of the United

States National Wildlife Refuge system located approximately $55 \mathrm{~km}$ off the southwest tip of Haiti. Though uninhabited, it is frequently visited by Haitian subsistence fishers. Reef development mostly occurs on the narrow shelf along the leeward southwest coast of the 
80 somewhat triangular island, whereas low-relief reef communities are found along the exposed

81 north coast (Fig 1). Benthic habitats along the windward east coast mainly consist of rubble

82 bottom. Due to its remoteness, there has been no structured monitoring program at Navassa.

83 Instead, episodic, opportunistic cruises have gathered both demographic and photoquadrat/cover

84 data. The opportunistic cruises were not intentionally designed to provide a rigorous comparison

85 across methodologies. Thus, here we leverage the only available data for a remote Caribbean

86 reef system starting from a relatively unimpacted baseline (Miller \& Gerstner 2002) by laying

87 out parallel observations derived from two separate coral sampling schemes, collected within

88 coherent time and habitat strata, to examine the observed differences to determine what

89 meaningful and complementary inferences can be discerned.

90

91

92

93

94

95

\section{Photoquadrat data}

A set of sites along the southwest shelf of Navassa (depth 18-34m), was sampled with haphazardly-placed, photoquadrats in 2002, 2004, 2006, 2009, and 2012. In 2002 and 2004 the sites were haphazardly selected (but always targeting reef habitats along the southwest coast) by necessity, as no habitat maps were available. Within the logistic constraints of working from a single large ship with multiple cruise objectives, effort was made to disperse these sites throughout the southwest shelf reef habitats. Later, the development of habitat maps from efforts on the 2004 cruise (Miller et al. 2008b) enabled the stratified-random selection of sampling sites in 2006, 2009, and 2012, similarly restricted to patch- and slope- reef habitats along the southwest coast in order to be comparable to sets of sites sampled in earlier years. Although the means of site selection varied between sample years, a relatively high sampling intensity (hence a representative sample given the restriction of habitat strata) was accomplished in each year (e.g., $>2$ sites $\mathrm{km}^{-2}$ shelf area in $2004,>4$ sites $\mathrm{km}^{-2}$ shelf area in the other years, e.g., Fig $1 \mathrm{~b}$ ). 
104 prior quadrat and then tossing the quadrat forward while the diver's eyes were closed, yielding

105 approximately 6-8 $\mathrm{m}$ distance between quadrats. Each photoquadrat was comprised of a $1 \mathrm{~m}^{2}$

106 image and a close-up of each quadrant of the quadrat (to provide a clearer image for reference to

107 aid in coral identification), for a total of five images per quadrat. Benthic community structure

108 was analyzed by overlaying each $1 \mathrm{~m}^{2}$ picture with $100(2002-4)$ or 50 (2006-12) random point

109 counts (reduced over time because large numbers of points per frame do not contribute to

110 improved power; Aronson et al. 1994; Houk \& Van Woesik 2006) using CPCe software (Kohler

$111 \&$ Gill 2006). Corals were identified to species when possible, genus if not. Eight to ten quadrats

112 were analyzed per site.

113 Variation over time in percent live coral cover was analyzed for the community as a

114 whole (all species summed) as well as for the most common individual taxa (Orbicella spp.

115 [primarily O. faveolata], Agaricia spp. [primarily A. agaricites], and branching Porites) via

116 separate one-way ANOVAs on ranks followed by Dunn's post-hoc tests for differences among

117 individual years. To make parallel, taxa-specific comparisons in percent cover as for the density

118 data (described below), we additionally performed separate Mann-Whitney rank sum tests to test

119 for differences in cover for each of three rarer taxa (Siderastrea siderea, Meandrina meandrites,

120 and Stephanocoenia intersepta) between 2004 and 2012.

121 Coral demographic data

122 In 2004 and 2012, coral colonies were surveyed at a separate set of haphazardly selected

123 reef sites (Table 1; including a subset of the stratified-random photoquadrat sites in 2012), with

124 effort to disperse these sites among the patch reef and slope reef habitats of the southwest and

125 north coasts (Fig 1). This demographic sampling was accomplished via belt transects (15m $\mathrm{x}$ 
$1260.5 \mathrm{~m}[2004]$ or $10 \mathrm{~m} \times 1 \mathrm{~m}$ [2012]), with short dive times due to deep depths sometimes dictating

127 a smaller sample area. The actual area sampled was recorded for each transect and used to

128 standardize colony density (as \# colonies $\mathrm{m}^{-2}$ ). Within each belt transect, every colony (defined

129 as all tissue sharing a single skeletal unit, even if multiple live tissue isolates were divided by

130 areas of dead skeleton) was identified to species, and size was recorded for most colonies

131 (Porites astreoides, was tallied for density but not sized in 2012 due to dive time constraints). In

132 2004, a clear acetate grid was overlaid the colony and used to estimate projected live colony area

133 directly. In 2012, the dimensions of each colony (maximum diameter and the diameter

134 perpendicular to the maximum) and a visual estimate of its projected $\%$ live area were recorded

135 in situ as was deemed more consistent to apply among multiple observers and to conform to

136 regionally established protocols (AGRRA; http:/www.agrra.org/method/methodhome.html). To

137 compare colony areas with those measured in 2004, a circular area (2-dimesional, projected) was

138 estimated with a diameter that was the average of the two diameters measured, and adjusted for

139 the estimated \% live area of the colony (adjusted circular area). While the adjusted circular area

140 and acetate grid are different means to estimate area, all field methods represent approximations

141 and these are both reasonable, comparable methods. Other efforts specifically aimed and

142 comparing different geomentric approximations for coral colony size/area have shown negligible

143 differences (e.g., between using a circular versus elliptical approximation for $2 \mathrm{~d}$ colony area; Van

144 Woesik et al. 2011). Colonies of less than $2 \mathrm{~cm}$ diameter $\left(3.14 \mathrm{~cm}^{2}\right.$ area) were excluded from

145 subsequent analyses to account for potential observer bias in the detection of small colonies and

146 inherent difference in detectability between years or transects due to variable cover of the

147 macroalga, Lobophora variegata. Identification uncertainties for the smaller juveniles also 
148 dictated pooling of certain taxa (mostly to genus, though Porites was delineated into branching

149 and mounding morphologies; see list in Fig 3).

$150 \quad$ For both coral density and multivariate community structure analyses, only transects

151 located along the southwest (leeward) coast of the island between $18-34 \mathrm{~m}$ depth were included

152 to standardize the sampled habitat in these analyses where including replicates in different

153 habitats would increase variance and decrease power. A smaller sampling effort did occur along

154 the north coast in each year (Table 1), but the reef habitats and benthic assemblage found here

155 are substantively distinct (Miller et al. 2008b) relative to the more-developed southwest reefs. ).

156 However, since the colonies along the north and southwest coasts clearly do not represent

157 distinct populations (being separated by $<1 \mathrm{~km}$ distance) and sampling effort was similar

158 between years (Table 1), all colonies available (including the north coast) were pooled for the

159 within-taxa size frequency analyses (described below) where pooling habitats helped boost

160 sample size.

161 Coral density was tallied for each transect ( $\mathrm{n}=17$ for 2004,18 for 2012) along the

162 southwest coast for 15 taxa in each year to generate mean abundance estimates of coral species

163 found in Navassa's high relief reef habitat. Univariate Mann-Whitney rank sum tests (or t-tests)

164 were used to test for univariate differences in density between years for each taxon and for total

165 coral density using transects as replicates. To characterize potential differences in coral

166 assemblage structure between 2004 and 2012, we calculated Bray-Curtis similarities on species

167 density estimates among all transects after square-root transforming the data to reduce the

168 influence of highly dominant taxa (Clarke \& Warwick 2001). A non-metric Multi-Dimensional

169 Scaling (nMDS) plot was created to visualize differences in coral composition of transects

170 between years while Analysis of Similarity (ANOSIM) was used to determine significance of 
171 these differences. Similarity Percentage (SIMPER) analysis was applied to identify which taxa

172 were most influential in determining significant difference between years (PRIMERe v. 6.0).

173 In analyzing potential differences in size structure of coral populations, we focussed on

174 taxa with $n>30$ colonies sized in each year. Colony areas were ln-transformed (Vermeij and

175 Bak 2002) and histograms constructed for each sampled year (2004 and 2012). Descriptive

176 statistics were calculated and the distribution of colonies among size classes was compared

177 between years via Kolmogorov-Smirnov tests for each taxa. Taxa not consistently measured in

1782012 (due to dive time constraints [i.e. Porites astreoides]) are not included in analyses of size

179 frequency.

180 Lastly, the individual colony areas (measured taxa only) for each transect were summed

181 by taxa and divided by the transect area. This yields a demographically-derived estimate of coral

182 cover (as coral area) to provide an integration of the (potentially contrasting) density and size

183 differences among taxa. This allows visualization of contrasts in assemblage composition

184 according to different 'currencies' (density versus area occupied) within the same demographic 185 data set.

186 This research was conducted under Navassa National Wildlife Refuge Special Use

187 Permits \#41529-2002-10, \#41529-2004-12 and \#41529-2006-03, \#41529-2009-01, and \#41529-

188 2012-001 from the US Fish and Wildlife Service.

189 RESULTS:

190 Photoquadrat data

191 The average photo-derived coral cover along the southwest coast of Navassa declined

192 from $34 \%$ in 2002 to $9.6 \%$ in 2012.2002 and 2004 do not differ significantly from each other, 
193 but they both are significantly higher than the subsequent three survey years (Fig 2, Dunn's post-

194 hoc pairwise comparisons). Orbicella spp. (predominantly O. faveolata) constituted about three-

195 quarters (0.76) of total coral cover in 2002, but only one fifth (0.20) of coral cover in 2012 with

196 the steepest (and statistically significant) decline between 2002 and 2004, prior to the

197 demographic sampling (Fig 2). In contrast, the other two taxa with the highest cover showed

198 more gradual declines and retained similar proportional representation of total cover over the

199 same time frame (0.20 to 0.23 for Agaricia spp. and 0.19-0.23 for branching Porites) (Fig 2).

200 Coral demographic data

201 In contrast to total photo-derived coral cover, total coral density along the southwest

202 coast did not differ between 2004 and 2012 (Table 1, t-test $\mathrm{p}=0.33$ ). However, significant

203 differences in species composition did occur (Global R=0.308; significance level of $0.1 \%$; Fig 3)

204 with S. siderea, A. agaracites, branching Porites, Leptoseris cucullata, and Orbicella spp. being

205 the taxa contributing foremost to the dissimilarity between the two years, cumulatively

206 contributing $45 \%$ of the total dissimilarity (SIMPER analysis). When analyzed separately

207 (univariate Mann-Whitney rank sums tests), A. agaricites, L. cucullata, and Orbicella spp. all

208 showed significant univariate decreases in density whereas branching Porites did not show any

209 significant difference between 2004 and 2012 (Fig 4). Coral species exhibiting significantly

210 higher colony density in 2012 included one common species, $S$. siderea, and two rarer species,

211 Stephanocoenia intersepta (formerly S. michelini) and Meandina meandrites (Fig 4). In

212 comparison, the photo-derived coral cover similarly captured a significant increase between 2004

213 and 2012 in $S$. siderea (from 0.41 to $0.97 \%$ cover; $U=57, p=0.039$ ), but no significant change

214 was detected for $M$. meandrites ( 0.10 to $0.20 \%$; $\mathrm{U}=100, \mathrm{p}=0.864)$ nor $S$. intersepta which was 
215 not identified in any of the photoquadrats in 2012 , though it was detected at low abundance (a 216 mean of .013\%) in 2004.

217 Robust coral size frequency distribution comparisons ( $\mathrm{n} \geq 100$ colonies) were obtained for

218 four taxa and for another four taxa based on smaller sample sizes $(n=30-99)$ (Table 2; three

219 additional taxa were recorded but lacked sufficient sample size for comparisons between years).

220 All four of the taxa with larger sample sizes show significant changes in size frequency

221 distributions between 2004 and 2012 (Fig 5a-d, Table 2). Orbicella spp. populations showed

222 smaller mean colony size ( $985 \mathrm{~cm}^{2}$ in 2004 to $347 \mathrm{~cm}^{2}$ in 2012), while branched Porites spp., $S$.

223 siderea, and A. agaracites had larger mean colony sizes. Of the four taxa with lower sample

224 size, only L. cucullata showed a significant difference (Fig 5e, Table 2), in this case shifting to a

225 larger mean colony size. Skewness shifted from positive to negative for four of the taxa ( $A$.

226 agaricites, branched Porites, L. cucullata, and S. intersepta) indicating increased under-

227 representation of small (or over-representation of large) colonies in these populations (Table 2;

228 Vermeij et al. 2007).

229 Pooling the area occupied by measured corals, juxtaposed with their cumulative density

230 (Fig 6) aids in integrating the contrasting patterns of decreased cover, stable density, and

231 contrasting size changes among taxa. The calculated area occupied by these corals in 2012 is

232 less than half of that in 2004, despite only small (insignificant) change in colony density.

233 Additionally, individual taxa show contrasting patterns between area and density units, due to the

234 influence of different size structure. While Orbicella spp. showed small losses (a factor of 0.36)

235 in density between 2004 and 2012, its losses in calculated area were extreme (less than one tenth

236 remained due to loss of large colonies). In contrast, $S$. siderea showed much greater increases in

237 density (tripled) than in area occupied (due to increased abundance constituted by small colonies 
238 occupying little area). Meanwhile, some taxa (e.g., A. agaricites) showed approximately

239 proportional changes in both units (Fig 6).

240 DISCUSSION:

241 The overall decline in coral cover and lack of resilience displayed among Caribbean reefs

242 over the past decades is well described in the literature. A large meta-analysis covering sites

243 throughout the Caribbean from 1970-2012 (Jackson et al. 2014) provides context for the changes

244 described here in Navassa reefs in the later portion of this interval. This meta-analysis indicates

245 the mean corrected coral cover for deeper reefs (5-20m depth, 88 locations) over three time

246 periods declined from $32.6 \%$ (1970-1983) to $19.4 \%$ (1984-1998) to 16.5 (1999-2012)(Jackson et

247 al. 2014, Part 1, Table 3, p.67). Though most of our Navassa sampling sites in all years were

248 deeper than 20m, the initial coral cover documented at Navassa's southwest reefs in this study

249 was $34 \%$ in 2002, corresponding with the Caribbean-wide average several decades earlier.

250 Subsequently, a 20\% absolute decline in Navassa coral cover occurred over a period of just four

251 years, whereas the Caribbean- wide mean decline of only $16 \%$ absolute took two decades. While

252 coral cover at Navassa does appear to have remained robust for a longer duration in the absence

253 of local development and human habitation, acute disturbance events of global stressors such as

254 thermally-induced coral bleaching (Miller et al. 2011) and coral disease (Miller \& Williams

255 2006) have coincided at Navassa with at least as great a magnitude of decline at a much more

256 rapid pace than the regional average.

257 We acknowledge several caveats to the data presented here when interpreting our

258 findings. The sites sampled in most cases were haphazardly chosen. However, all sites sampled

259 in both data sets were constrained by habitat type for each temporal comparison (e.g., to deep

260 patch and bank reefs on the southwest coasts for coral density). The total shelf area at Navassa is 
261 small and the relative density of sampled sites was adequate to detect differences between years

262 in both cover and demographic parameters. The demographic data were collected

263 opportunistically to supplement $\%$ cover monitoring data, not as planned repeat monitoring or a

264 methods comparison. Furthermore, our sampling in both years was constrained by a limited

265 number of dives per cruise to survey the coral community, not shaped by an objective power

266 analysis nor optimal spatial allocation of samples (e.g., Smith et al. 2011). The sampling effort

267 (i.e. person dives and area covered) was fairly similar between both data sets in 2004, but

268 somewhat higher for the demographic data in 2012 (Table 1). Given this non-homogenous field

269 sampling, we took a conservative approach to our analyses. Our analytical approach has been to

270 filter the demographic data in conservative ways to avoid potential bias in the primary

271 comparison between years i.e., excluding (e.g. small sizes) or pooling (e.g. nominal spp

272 identifications into higher taxa groups) data whenever there was uncertainty in comparability.

273 Given this sub-optimal data set, interesting and significant differences between years are evident

274 from the demographic data (Fig 4, Table 2) that are not resolvable from the more traditional and

275 more frequent coral cover data.

276 Significant loss in coral cover occurred while total coral density remained unchanged, as

277 substantially lower colony abundance of some taxa (mainly Orbicella spp) was offset by

278 significantly higher density of other, typically smaller taxa. These taxa with higher density

279 include both the common $S$. siderea (for which increase was also apparent from the more

280 frequent photo-derived cover data), as well as two rare species for which changes in photo-

281 derived cover were not discernable (M. meandites and S. intercepta). High recruitment rates

282 have similarly been reported for these three species in other studies (e.g., Huntington \& Lirman

283 2012; Vermeij et al. 2011). Historic studies of juvenile coral assemblages in Curaçao indicate $M$. 
284 meandrites ranking $4^{\text {th }}$ and $S$. intersepta $7^{\text {th }}$ in terms of relative abundance within the total

285 juvenile population (Bak \& Engel 1979). For M. meandrites, our 2004 mean density of 0.09

286 colonies $\mathrm{m}^{2}$ is congruent with that reported by Pinzon and Weil (2011) measured in southwest

287 Puerto Rico in 2002-3, as is a negative skewness of its size distribution. However, this species

288 showed a decrease in juvenile density in Curaçao between 1979 and 2005 (Vermeij et al. 2011),

289 and we are unaware of other published reports of significant increasing abundance trends for this

290 species as observed at Navassa (Fig 4). Interestingly, L. cucullata, a significant 'loser' in colony

291 abundance in the current study, has showed a similar drastic decrease in juvenile density in both

292 Curaçao (as Helioseris cucullata; (Vermeij et al. 2011) and Jamaica (Hughes \& Tanner 2000).

293 The size frequency data showed that some species shifted significantly toward larger

294 colonies, and others toward smaller size. The loss of very large Orbicella spp. colonies is most

295 likely attributable to substantial mortality associated with disease and bleaching events between

2962004 and 2006 (Miller et al. 2011; Miller \& Williams 2006 ). The most drastic difference in size

297 distribution among the taxa examined was a strong shift to larger colonies in branching Porites.

298 The reason for this remains unclear, but a reduction in recruitment combined with growth of

299 colonies through time (from a modal diameter of $3 \mathrm{~cm}$ to a modal diameter of $14 \mathrm{~cm}$ in eight

300 years, Fig 5B) seems plausible, given no significant change in density (Fig 4). Alternatively, it is

301 possible that a substantial shift in species representation within this morphological group may

302 have occurred (e.g., more $P$. porites and less of the small $P$. furcata and/or $P$. divaricata). We

303 do not think this explanation likely due to substantial representation by both small and larger

304 morphs in both sampling years, and recent genetic evidence has failed to support these three as

305 distinct species (Prada et al. 2014). 
307 data in deep water reefs where bottom time is limiting. The present data sets were collected with

308 roughly comparable levels of in-water effort per unit sample (at the depths and dive times

309 available for these deep reefs, a single diver was able to complete either one demography

310 transect or a set of photoquads, each method surveying $\sim 10 \mathrm{~m}^{2}$ of the seafloor, Table 1 ),

311 though there are clear tradeoffs in both the amount of post-processing effort required and aspects

312 of statistical power related to ten replicate photoquads versus a single transect that yields data on

313 a large but variable number of coral colonies. The consequences of these replication differences

314 will depend on the types of analyses attempted. Fundamentally, the methods pose different

315 questions-- \% cover provides a picture of the overall coral community composition and enables

316 comparison across other competing benthic taxa (algae, sponges, etc), whereas demographic

317 surveys are necessarily species inventories aimed at characterizing populations. For sampling of

318 deep water reefs, the decision to use photoquads, demography transects, or both methods should

319 be based on the underlying questions motivating the survey.

320 Demographic and percent cover approaches can both pose pitfalls. For example,

321 increasing frequencies of small colonies can result from beneficial processes such as recruitment

322 of new colonies or undesirable processes such as partial mortality resulting in small remnant

323 colonies. Meanwhile, a single massive colony is not functionally equivalent (in terms of habitat

324 value, susceptibility to various threats, nor fecundity) to many small colonies but might be

325 represented as equal in terms of percent cover. Photoquadrats do not necessarily sample every

326 coral in the area surveyed, and can have poorer resolution or detectability for rare, small, or

327 similar-appearing species. For example, we were not able to quantify L. cucullata abundance

328 reliably from our photos (likely mis-identified as Agaricia spp., or present in cryptic locations 
329 not visible in top-down photographs) whereas it was easily distinguishable in the field. Hence,

330 the significant loss of this species (sixth most common taxon in 2004) would not have been

331 detected from photoquadrat sampling alone. The decline of $L$. culcullata, also reported in

332 Curacao (Vermeij et al. 2011) and Jamaica (Hughes \& Tanner 2000), is likely the most

333 substantial collapse of a Caribbean coral species since Acropora spp. but has largely gone

334 unnoticed due to predominance of photographic monitoring approaches.

335 Most long-term coral monitoring efforts have relied solely on percent cover to quantify

336 abundance, community structure, and changes through time. This approach has been sufficient

337 to detect changes over long time frames (De'ath et al. 2012) and the drastic losses over short time

338 frames due to recent acute disturbances on Atlantic/Caribbean reefs (e.g., Coelho \& Manfrino

339 2007; Miller et al. 2009). Significant declines are relatively easy to detect from a baseline of

$34050 \%$ cover, but change detection likely requires much greater sampling effort from a baseline

341 signal of $10 \%$, or even much lower for individual coral species, as characterizes most modern

342 Caribbean reefs (e.g., Gardner et al. 2003; Ruzicka et al. 2013). Within the photoquadrat data set

343 reported here, significant change is detectable over less than a decade in coral percent cover and

344 even in the few dominant individual coral taxa (Fig 2). However, given the low percent coral

345 cover in Navassa by the end of the study period, it seems highly unlikely that future changes in

346 total coral cover (either continued decline from a low baseline or, hopefully, recovery), let alone

347 individual taxa, will be detectable over the next decade without substantially greater sampling

348 effort if relying on photoquadrat sampling alone. For example, Molloy et al. (2013) performed

349 intensive power analyses to determine the number of photoquadrats/points required to detect $1 \%$

350 per annum recovery in coral cover and concluded this scale of recovery was essentially

351 impossible to detect with their most intensive photoquadrat protocols ( 250 quadrats per site, 50 
352 points per quadrat). While traditional percent cover data such as from photoquadrats provides

353 crucial information on the status of the 'other $90 \%$ ' of the reef that is not hard coral, it may

354 provide relatively less information for corals, especially when they are at low abundance. By

355 supplementing photoquadrat data with minimal demographic sampling we were able to detect

356 increased densities of several species over eight years. The collection of colony-based (i.e.

357 demographic) data provide additional metrics, greater resolution and analytical power (e.g.,

358 hundreds of colonies for many taxa in an effort such as this, rather than a cover estimate of, e.g.,

$359<1 \%$ ), and a valuable mechanistic insight as to the population dynamics driving coral population

360 changes. Hence, a combined approach employing both photoquadrat data with demographic data

361 may be the most informative to track changes in benthic reef communities at low coral

362 abundances.

363

364 ACKNOWLEDGEMENTS: This work was made possible by the excellent logistic support

365 provided by D McClellan, J Javech, the John G. Shedd Aquarium's R/V Coral Reef II, the

366 NOAA Ship Nancy Foster, and the LOF's M/Y Golden Shadow. Special thanks to A Bruckner

367 (LOF) for enabling 2012 data collection. 
370

371

372

373

374

375

376

377

378

379

380

381

382

383

384

385

386

387

388

389

390

391

392

393

394

395

396

397

398

399

400

401

402

403

404

405

406

407

408

409

410

411

412

Aronson RB, Edmunds PJ, Precht WF, Swanson DW, and Levitan DR. 1994. Large-scale, longterm monitoring of Caribbean coral reefs: Simple, quick, inexpensive techniques. Atoll Research Bulletin 421:1-19.

Bak RPM, and Engel MS. 1979. Distribution, abundance and survival of juvenile hermatypic corals (Scleractinia) and the importance of life history strategies in the parent coral community. Marine Biology 54:341-352.

Bak RPM, and Meesters EH. 1998. Coral population structure: The hidden information of colony size-frequency distributions. Marine Ecology Progress Series 162:301-306.

Clarke KR, and Warwick RM. 2001. Change in marine communities: an approach to statistical analysis and interpretation, 2nd edition. Plymouth: PRIMER-E.

Coelho VR, and Manfrino C. 2007. Coral community decline at a remote Caribbean island: marine no - take reserves are not enough. Aquatic Conservation: marine and freshwater ecosystems 17:666-685.

De'ath G, Fabricius KE, Sweatman H, and Puotinen M. 2012. The 27-year decline of coral cover on the Great Barrier Reef and its causes. Proceedings of the National Academy of Sciences 109:17995-17999.

Done T. 1985. Effects of two Acanthaster outbreaks on coral community structure-the meaning of devastation. Proc 5th Int Coral Reef Symp 5:315-320.

Gardner TA, Cote IM, Gill JA, Grant A, and Watkinson AR. 2003. Long-term region-wide declines in Caribbean corals. Science 301:958-960.

Houk P, and Van Woesik R. 2006. Coral reef benthic video surveys facilitate long-term monitoring in the Commonwealth of the Northern Mariana Islands: toward an optimal sampling strategy. Pacific Science 60:177-189.

Hughes TP. 1984. Population dynamics based on individual size rather than age: A general model with a reef coral example. American Naturalist 123:778-795.

Hughes TP, and Tanner JE. 2000. Recruitment failure, life histories, and long-term decline of Caribbean corals. Ecology 81:2250-2263.

Huntington BE, and Lirman D. 2012. Species-area relationships in coral communities: evaluating mechanisms for a commonly observed pattern. . Coral Reefs 31:929-938.

Jackson JBC, Donovan MK, Cramer KL, and Lam VVe. 2014. Status and Trends of Caribbean Coral Reefs: 1970-2012. Gland, Switzerland: Global Coral Reef Monitoring Network, IUCN. p 304.

Kohler KE, and Gill SM. 2006. Coral Point Count with Excel extensions (CPCe): A Visual Basic program for the determination of coral and substrate coverage using random point count methodology. Computers and Geosciences 32:1259-1269.

Lang JC, and Ginsburg RN. 2006. A vision for regular, rapid assessments of the tropical northwestern Atlantic's coral reefs. Revista de Biologia Tropical:23-29.

Miller J, Muller E, Rogers C, Waara R, Atkinson A, Whelan KRT, Patterson M, and Witcher B. 2009. Coral disease following massive bleaching in 2005 causes $60 \%$ decline in coral cover on reefs in the US Virgin Islands. Coral Reefs 28:925-937.

Miller MW, and Gerstner CL. 2002. Reefs of an uninhabited Caribbean island: fishes, benthic habitat, and opportunities to discern reef fishery impact. Biological Conservation 106:3744. 
413 Miller MW, Gleason A, McClellan D, Piniak G, Williams D, Wiener J, Gude A, and Schwagerl

414

415

416

417

418

419

420

421

422

423

424

425

426

427

428

429

430

431

432

433

434

435

436

437

438

439

440

441

442

443

444

445

446

447

448

449

450

451

452

453
J. 2008a. The State of Coral Reef Ecosystems of Navassa Island. In: Waddell JE, and Clarke AM, eds. The State of Coral Reef Ecosystems of the United States and Pacific Freely Associated States: 2008. Silver Spring: NOAA Technical Memorandum NOS NCCOS 73. NOAA/NCCOS Center for Coastal Monitoring and Assessment's Biogeography Team., 117-229.

Miller MW, Halley RB, and Gleason A. 2008b. Biology and Geology of Navassa Island. In: Riegl B, and Dodge RE, eds. Coral Reefs of the USA: Springer, 407-433

Miller MW, Piniak GA, and Williams DE. 2011. Coral mass bleaching and reef temperatures at Navassa Island, 2006. Estuarine, Coastal and Shelf Science 91:42-50.

Miller MW, and Williams DE. 2006. Coral disease outbreak at Navassa, a remote Caribbean island. Coral Reefs 26:97-101.

Molloy P, Evanson M, Nellas A, Rist J, Marcus J, Koldewey H, and Vincent A. 2013. How much sampling does it take to detect trends in coral - reef habitat using photoquadrat surveys? Aquatic Conservation: marine and freshwater ecosystems.

Obura DO, and Grimsditch G. 2009. Resilience assessment of coral reefs - Assessment protocol for coral reefs, focusing on coral bleaching and thermal stress. . IUCN working group on Climate Change and Coral Reefs. Gland, Switzerland: IUCN. p 70.

Prada C, DeBiasse MB, Neigel JE, Yednock B, Stake JL, Forsman ZH, Baums IB, and Hellberg ME. 2014. Genetic species delineation among branching Caribbean Porites corals. Coral Reefs 33:1019-1030.

Ruzicka R, Colella M, Porter J, Morrison J, Kidney J, Brinkhuis V, Lunz K, Macaulay K, Bartlett L, Meyers M, Colee J. 2013. Temporal changes in benthic assemblages on Florida Keys reefs 11 years after the 1997/1998 El Nino. Marine Ecology Progress Series 489:125-141.

Smith SG, Swanson DW, Chiappone M, Miller SL, and Ault JS. 2011. Probability sampling of stony coral populations in the Florida Keys. Environmental Monitoring and Assessment 183:121-138.

Stoddart DR, and Johannes RE. 1978. Coral reef research methods. Paris: UNESCO.

Van Woesik R, Sakai K, Ganase A, and Loya Y. 2011. Revisiting the winners and the losers a decade after coral bleaching. Marine Ecology Progress Series 434:67-76.

Vermeij M, and Bak R. 2002. Inferring demographic processes from population size structure in corals. Proceedings of the 10th International Coral Reef Symposium 1:589-593.

Vermeij M, Frade P, Jacinto R, Debrot A, and Bak R. 2007. Effects of reproductive mode on habitat-related differences in the population structure of eight Caribbean coral species. MEPS 351:91-102.

Vermeij MJ, Bakker J, Hal Nvd, and Bak RP. 2011. Juvenile coral abundance has decreased by more than 50\% in only three decades on a small Caribbean island. Diversity 3:296-307. 


\section{Table $\mathbf{1}$ (on next page)}

Summary effort and density

In-water effort for 2004 and 2012 demographic ('Demo') and photoquadrat (PQ) sampling including number of sites, transects or photoquadrats and person-dives. Area $\left(\mathrm{m}^{2}\right)$ indicates the cumulative area of transects (demo) or quadrats sampled. The total number of colonies sampled and the colony density (\# colonies $/ \mathrm{m}^{2}$ ) are also given under the demographic section. 
1 Table 1. In-water effort for 2004 and 2012 demographic ('Demo') and photoquadrat (PQ)

2 sampling including number of sites, transects or photoquadrats and person-dives. Area $\left(\mathrm{m}^{2}\right)$

3 indicates the cumulative area of transects (demo) or quadrats sampled. The total number of

4 colonies sampled and the colony density (\# colonies $/ \mathrm{m} 2$ ) are also given under the demographic 5 section.

6

\begin{tabular}{|l|l||l|l|l||l|l|l|l|l|l|}
\hline Year & Location & $\begin{array}{l}\text { PQ \# } \\
\text { sites }\end{array}$ & $\begin{array}{l}\text { PQ } \\
\text { area }\end{array}$ & $\begin{array}{l}\text { PQ } \\
\text { person } \\
\text {-dives }\end{array}$ & $\begin{array}{l}\text { Demo } \\
\text { \# sites }\end{array}$ & $\begin{array}{l}\text { Demo \# } \\
\text { transects }\end{array}$ & $\begin{array}{l}\text { Demo } \\
\text { person } \\
\text {-dives }\end{array}$ & $\begin{array}{l}\text { Demo } \\
\text { area }\end{array}$ & \# col & $\begin{array}{l}\text { Overall } \\
\text { Density } \\
\text { (SE) }\end{array}$ \\
\hline 2004 & $\mathrm{SW}$ & 14 & 149 & 16 & 13 & 17 & 13 & 111.5 & 1227 & $11.48(1.06)$ \\
\hline & $\mathrm{N}^{*}$ & & & & 6 & 7 & 6 & 50.5 & 351 & $7.07(0.56)$ \\
\hline 2012 & $\mathrm{SW}$ & 12 & 125 & 13 & 8 & 18 & 20 & 166.5 & 1711 & $10.17(0.80)$ \\
\hline & $\mathrm{N}^{*}$ & & & & 4 & 6 & 5 & 51 & 316 & $6.18(0.46)$ \\
\hline
\end{tabular}

7

*Transects from the north coast are included only in the size frequency analyses (Table 2, Fig 4) 


\section{Table 2 (on next page)}

Size frequency data

Coral colony size frequency summary statistics from Navassa demographic sampling in 2004 and 2012, based on In(colony area $\left[\mathrm{cm}^{2}\right]$ ). P-values are given for Kolmogorov-Smirnov tests comparing distributions between the two years. Three sections indicate groups of taxa with progressively lesser N's. Histograms for taxa that are significantly different are shown in Fig 5. Taxa as in Fig 4. 


\begin{tabular}{|c|c|c|c|c|c|c|c|c|c|c|c|c|c|c|c|}
\hline & \multicolumn{6}{|c|}{2004} & \multicolumn{6}{|c|}{2012} & \multirow[b]{2}{*}{$p$} & \multirow[b]{2}{*}{$\mathrm{KS}$} \\
\hline & & Count & Mean & Median & Var & S.D. & $\begin{array}{l}\text { Skew } \\
\text { ness }\end{array}$ & Count & Mean & Median & Var & S.D. & $\begin{array}{l}\text { Skew } \\
\text { ness }\end{array}$ & & \\
\hline \multirow{4}{*}{-} & Aaga & 438 & 3.89 & 3.74 & 2.24 & 1.50 & 0.24 & 365 & 4.28 & 4.46 & 1.48 & 1.22 & -0.53 & $<0.001$ & 3.51 \\
\hline & Orb spp & 183 & 5.82 & 5.99 & 2.64 & 1.62 & -0.42 & 100 & 5.08 & 5.45 & 2.22 & 1.49 & -0.77 & $<0.001$ & 2.04 \\
\hline & \begin{tabular}{|l|} 
Por \\
Branched
\end{tabular} & 212 & 2.73 & 2.20 & 2.09 & 1.45 & 1.36 & 199 & 4.32 & 4.64 & 1.94 & 1.39 & -0.45 & $<0.001$ & 5.30 \\
\hline & Ssid & 154 & 2.85 & 2.48 & 1.63 & 1.28 & 1.18 & 422 & 3.12 & 2.98 & 1.59 & 1.26 & 0.47 & $<0.001$ & 2.32 \\
\hline \multirow{4}{*}{$=$} & Efas & 36 & 3.44 & 2.94 & 2.96 & 1.72 & 0.61 & 45 & 3.70 & 3.50 & 2.27 & 1.51 & 0.87 & 0.31 & 0.97 \\
\hline & Lcuc & 87 & 3.05 & 3.04 & 1.18 & 1.09 & 0.27 & 30 & 3.70 & 4.14 & 1.95 & 1.40 & -0.37 & 0.00 & 1.76 \\
\hline & Mcav & 31 & 3.63 & 3.30 & 3.36 & 1.83 & 0.78 & 46 & 3.59 & 3.42 & 2.21 & 1.49 & 0.30 & 0.81 & 0.64 \\
\hline & Sint & 41 & 3.40 & 3.30 & 1.51 & 1.23 & 0.53 & 96 & 3.53 & 3.50 & 1.54 & 1.24 & -0.03 & 0.19 & 0.83 \\
\hline \multirow{3}{*}{$\equiv$} & Dipl spp* & 5 & 6.95 & 7.90 & 2.60 & 1.61 & 0.46 & 5 & 6.49 & 6.63 & 2.21 & 1.49 & 0.07 & $\mathrm{n} / \mathrm{a}$ & $\mathrm{n} / \mathrm{a}$ \\
\hline & Mmea & 12 & 4.36 & 4.43 & 1.45 & 1.21 & -0.17 & 57 & 4.63 & 4.73 & 2.17 & 1.47 & -0.43 & $\mathrm{n} / \mathrm{a}$ & $\mathrm{n} / \mathrm{a}$ \\
\hline & Mycet spp & 18 & 3.54 & 3.47 & 1.58 & 1.26 & 0.46 & 11 & 3.37 & 3.65 & 1.67 & 1.29 & 0.07 & $\mathrm{n} / \mathrm{a}$ & $\mathrm{n} / \mathrm{a}$ \\
\hline
\end{tabular}

1 *Includes recently reclassified Pseudodiploria strigosa (Budd et al. 2012) 
Figure 1 (on next page)

Sample Location

Map showing location of Navassa Island in the greater Antilles. Insets show the specific location of demographic sites (a) and photoquadrat sites (b) that were sampled in 2004 and 2012. Photoquadrat sites sampled in the other years were similarly dispersed among reef habitats of the southwest coast (i.e., 2004 and 2012 are shown as representative examples). Site locations are superimposed on satellite imagery showing reef distribution along the Navassa shelf (IKONOS image provided by DigitalGlobe). 


\section{Figure 2 (on next page)}

Photo-derived percent cover

Percent cover ( + 1SE) for total scleractinian corals and for the three most abundant coral taxa in Navassa photoquadrats over time. The three most abundant taxa are Orbicella spp. (predominantly O. faveolata), Agaricia spp. (dominated by A. agaricites), and branching Porites (P. porites, $P$. furcata, and $P$. divaricata). P-values in legend from separate one-way ANOVA on ranks for each taxa across time. $\mathrm{N}$ (number of sites) is given for each year under the axis. Similar letters over each set of bars indicate no statistical difference in post-hoc comparisons for a given taxa across time. Note that Orbicella spp. cover had declined most before 2004, whereas the other two taxa (and total coral cover) continued declining through 2006. 


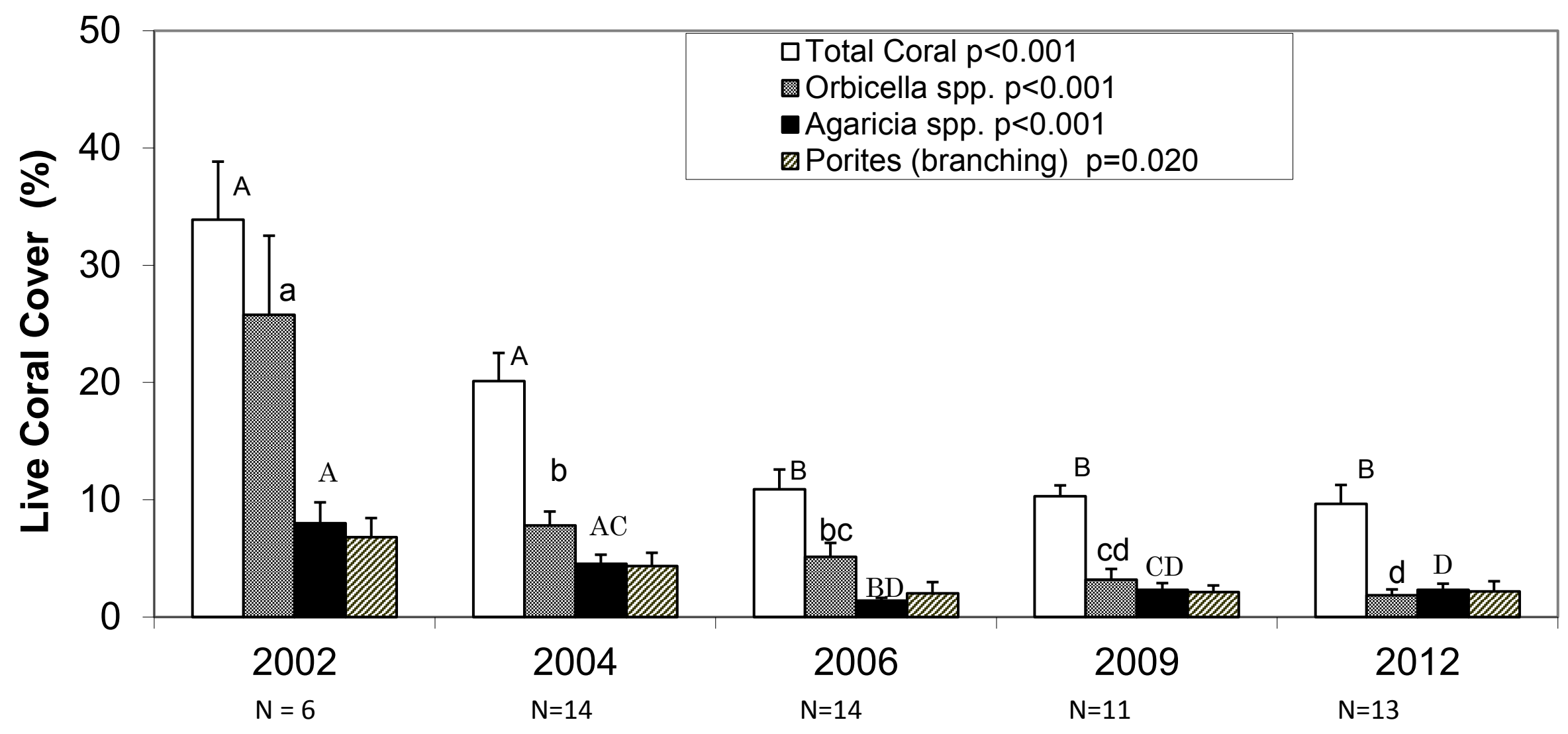


Figure 3 (on next page)

Community change

nMDS scaling plot for coral demographic transects sampled on the southwest coast of Navassa in 2004 (triangles) and 2012 (asterisks). Although the somewhat high stress level indicates that this 2-dimensional rendering is not a perfect representation of the similarity among samples, ANOSIM indicates significant change in coral community structure (based on square-root transformed colony density) between the two years (Global $\mathrm{R}=0.308$; significance level of $0.1 \%$ ). 


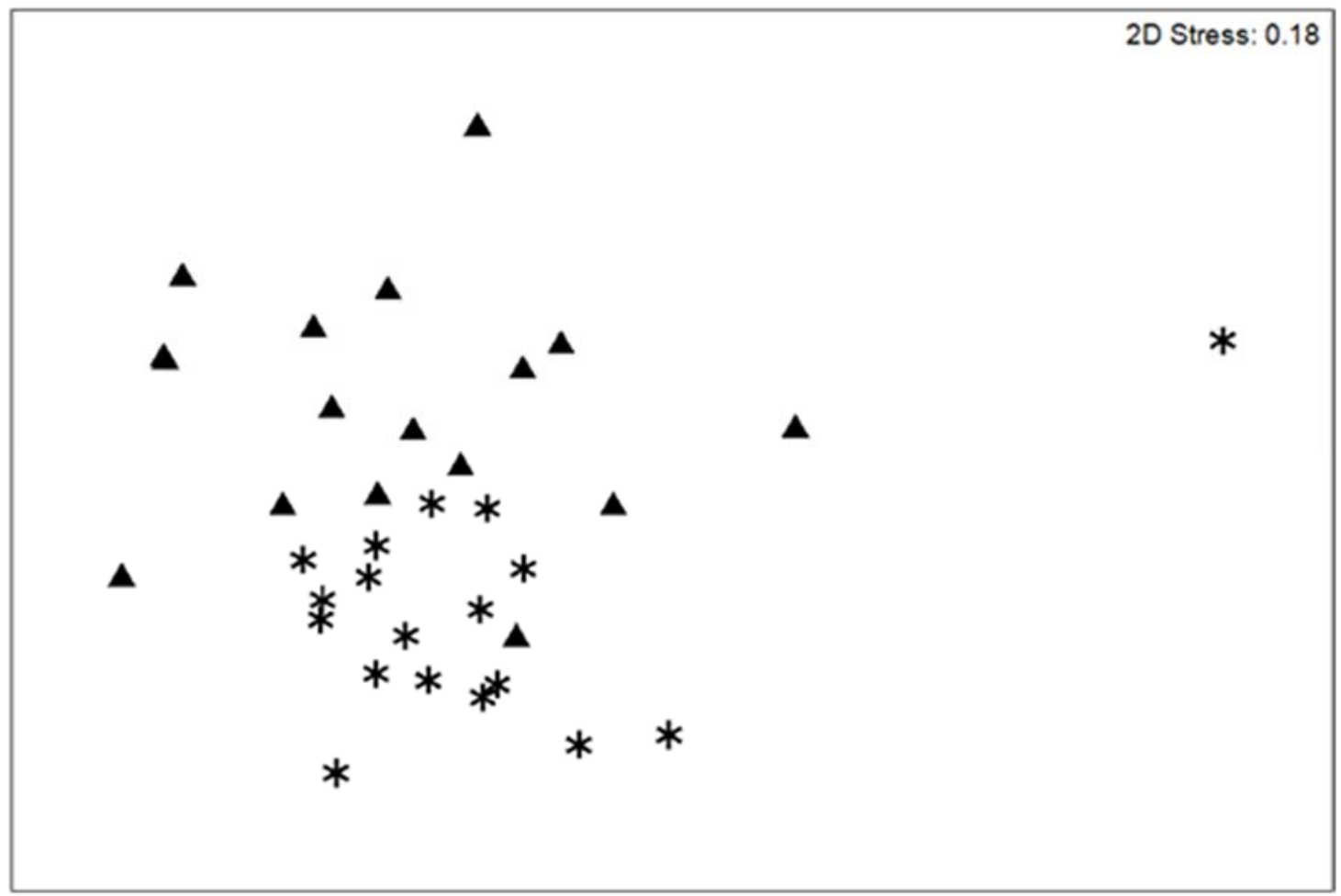




\section{Figure 4 (on next page)}

Colony density by taxa

Colony density for coral taxa (mean + 1SE; $n=17$, transects in 2004 and 18 in 2012) in the demographic sampling of sites along the southwest coast of Navassa. *indicates significant difference between the two years as determined by Mann-Whitney rank sum test $(p<0.05)$. Orb spp = Orbicella spp. (predominantly O. faveolata); Mcav = Montastraea cavernosa; Dipl spp = Diploria (includes recently reclassified Pseudodiploria strigosa, ( Budd et al. 2012 )) species; Por branched = branched Porites spp (P.porites, P.furcata, P.divaricata); Por Mound = mounding Porites species (predominantly P.astreoides); Ssid=Siderastrea siderea; Sint = Stephanocoenia intersepta; Mmea = Meandrina meandrites; Aaga=Agaricia agaricites; Other $\mathrm{Ag}=$ Agaricia species other than A.agaricites; Lcuc = Leptoseris cucullata; Efas = Eusmilia fastigiada; Mycet spp= Mycetophyillia species; Madr = Madracis species; Other = other scleractinians. 


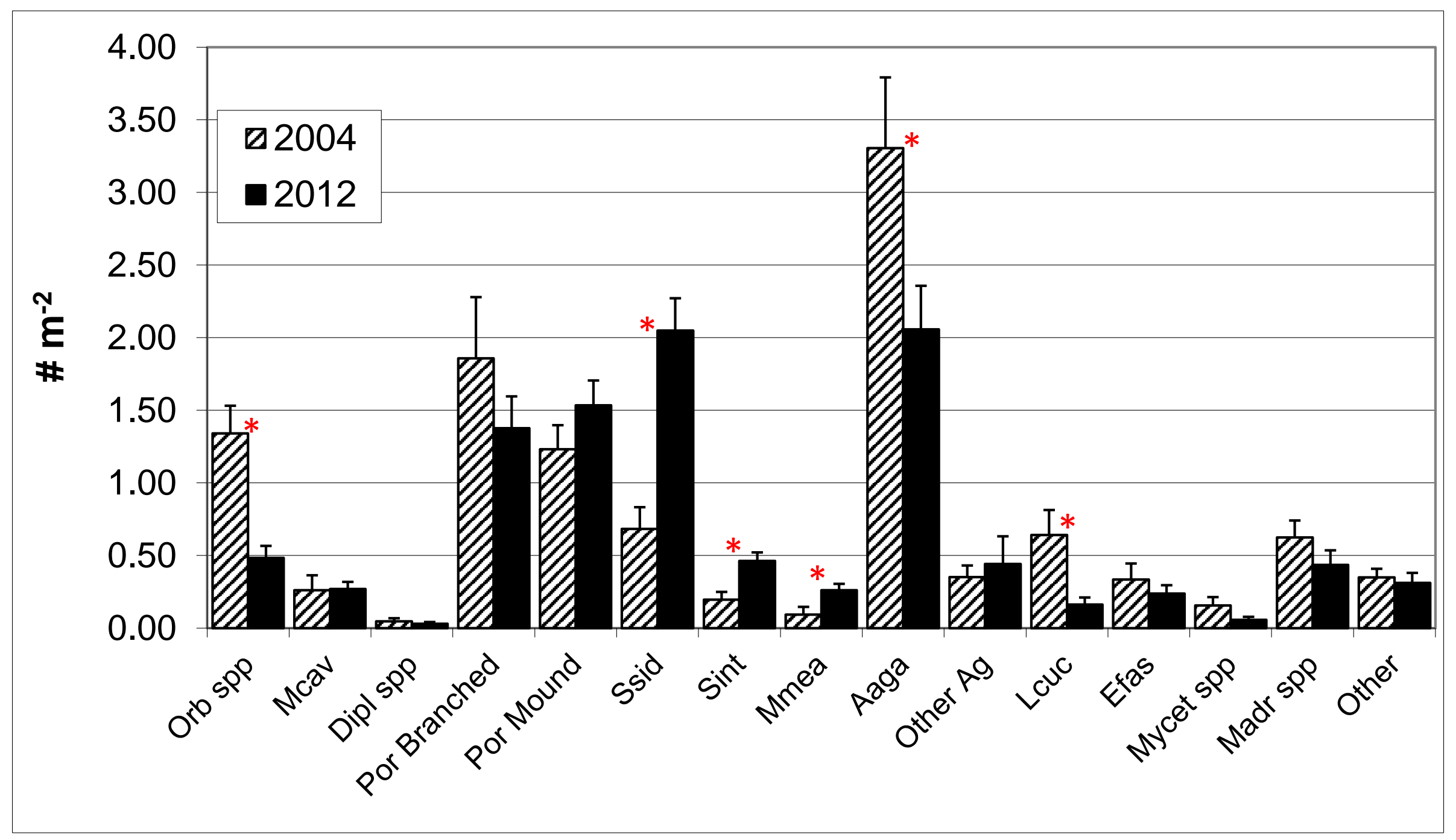




\section{5}

Size frequency distributions

Fig 5. Size frequency distributions for five taxa that showed significant difference between 2004 and 2012. Size bins are expressed as In (colony area in $\mathrm{cm}^{2}$ ). Corresponding colony diameters (for calculated circular area) are shown below the $x$-axis for scale. Summary statistics given in Table 2. Taxa as in Fig 4. 


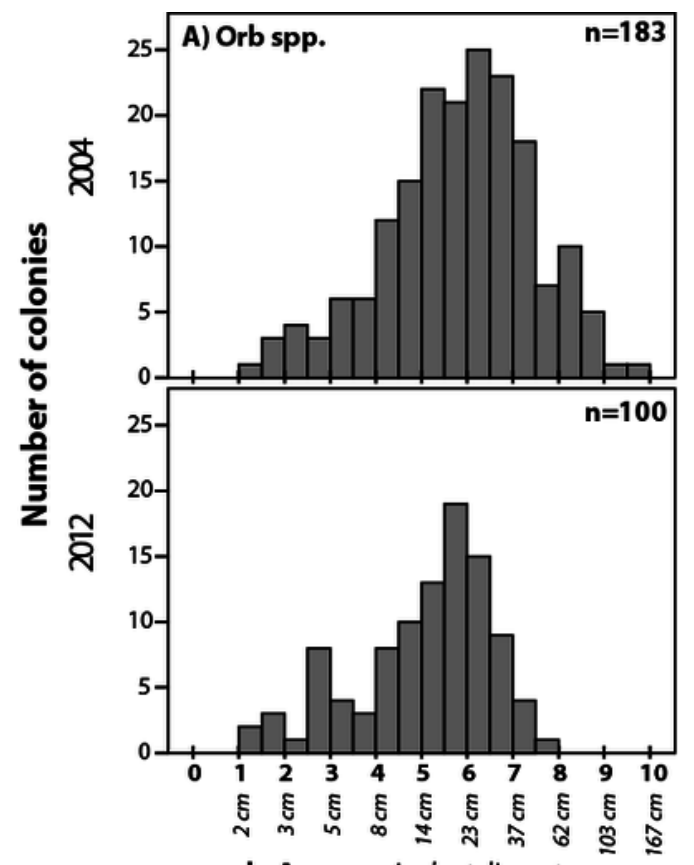

In Area, equivalent diameter

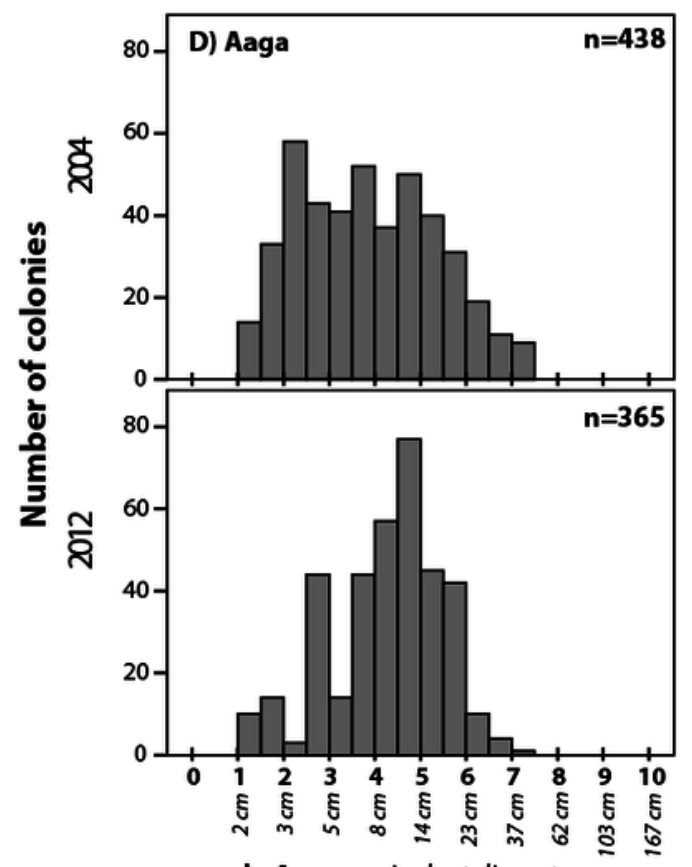

In Area, equivalent diameter
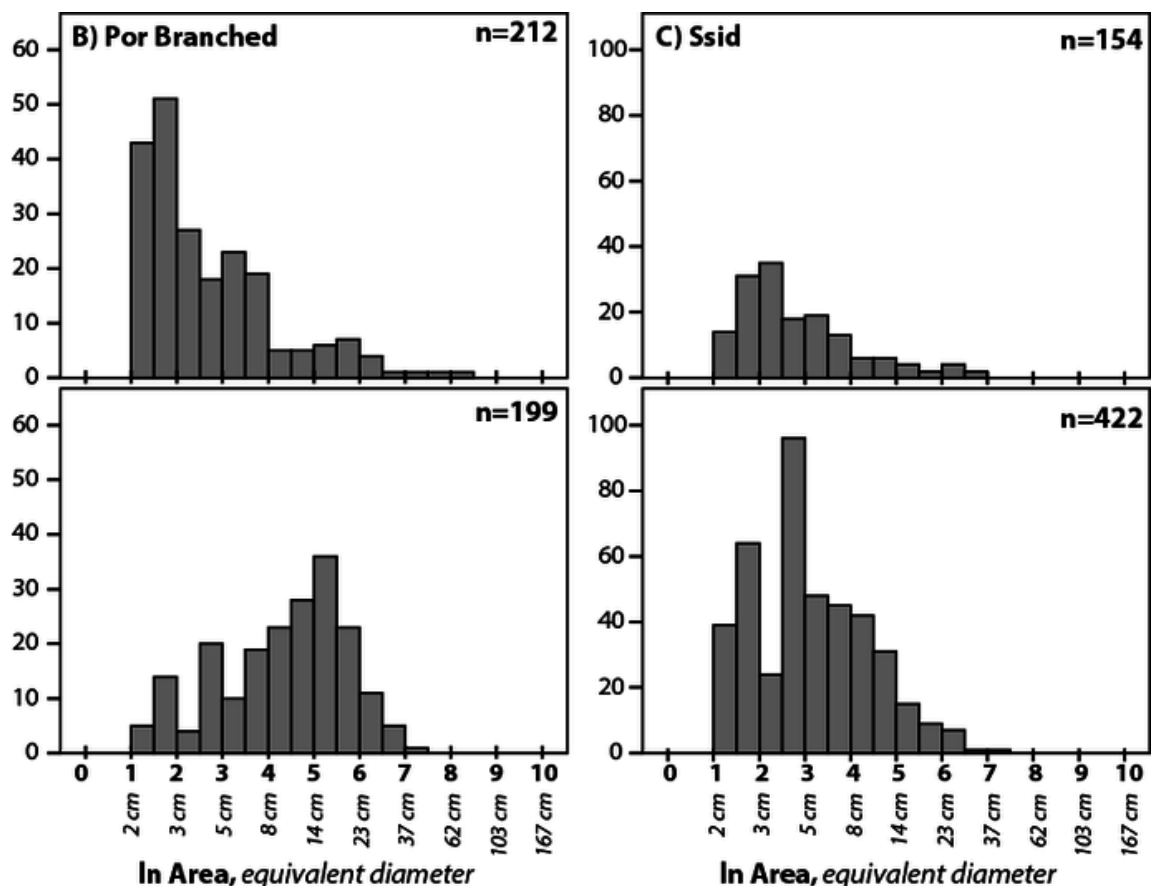

In Area, equivalent diameter

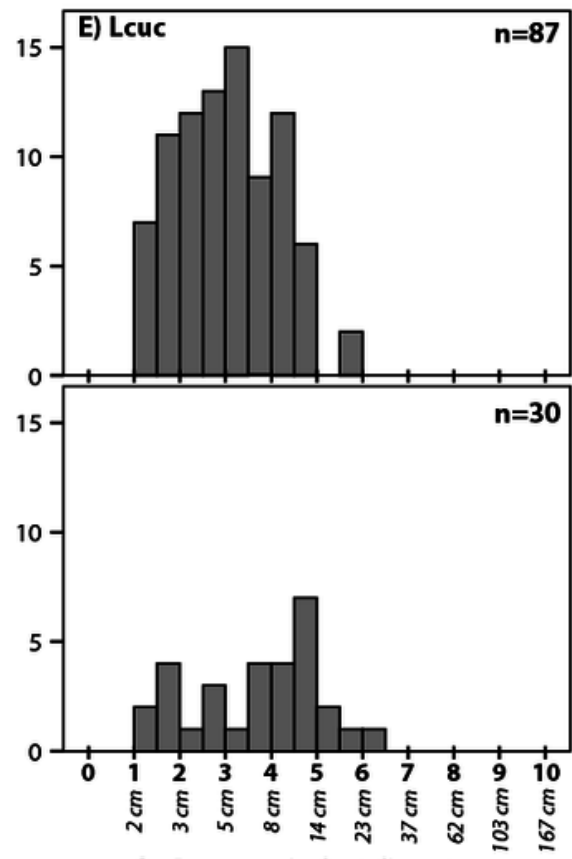

In Area, equivalent diameter 


\section{Figure 6 (on next page)}

\section{Area occupied by taxa}

A comparison of coral composition (sized taxa only) for southwest sites based on demographic data expressed as density $(A)$ and as area back-calculated by summing the area occupied by each of these sized colonies (B). Taxa abbreviations as in Fig 4. 

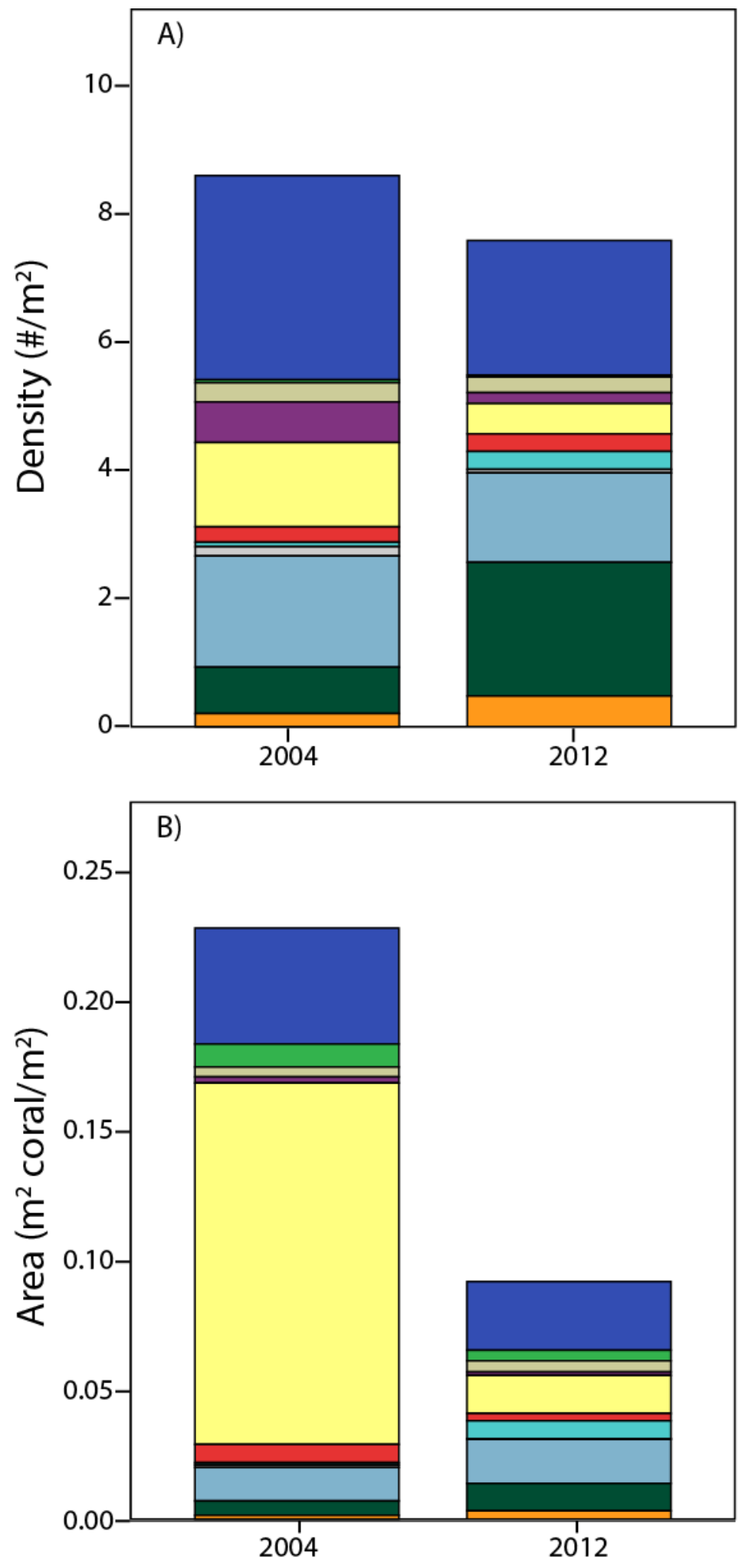

\begin{tabular}{l}
\hline Aaga \\
$\square$ Dipl spp \\
$\square$ Efas \\
$\square$ Lcuc \\
$\square$ Orb spp \\
$\square$ Mcav \\
$\square$ Mmea \\
$\square$ Mycet spp \\
$\square$ Por Branched \\
$\square$ Ssid \\
$\square$ Sint
\end{tabular}

